\title{
Are environmental health officers and transport planners in English local authorities working together to achieve air quality objectives?
}

\author{
A. O. Olowoporoku, E. T. Hayes, N. S. Leksmono, \\ J. W. S. Longhurst \& G. P. Parkhurst \\ Faculty of Environment and Technology, \\ University of the West of England, Bristol, UK
}

\begin{abstract}
Since 1997, Local Air Quality Management (LAQM) has been used as a process through which local authorities in England identify and manage specific air quality problems within their jurisdictions in order to achieve the air quality objectives (AQO). However, the limitation of this process is that of policy disconnect between diagnosis and solutions proffered within it. Over $90 \%$ of air quality 'hot-spots' identified through the LAQM are due to traffic-related sources. Hence, the air quality action plans prepared by the environmental health officers (EHO) are improperly calibrated as a policy instrument for tackling most of the problems discovered through the LAQM. The inclusion of air quality as one of the four shared priorities in the second round of the Local Transport Plan (LTP2) therefore implies that the EHO need to engage with the transport planners (TP) at the local level in order to address most of these problems i.e. traffic-related air pollution.
\end{abstract}

Since LAQM and LTP operate as two parallel frameworks with a separate agenda and timetable, adequate connectivity between both policy packages is thereby dependent on the type and level of inter-professional engagement between the departments and officials responsible for both policies at every level of government involved. This paper presents emerging issues from the questionnaire survey of EHO and TP in over 200 local authorities in 2007 as part of a three-year investigation into the effectiveness of achieving the AQO through the LTP in English local authorities. While there is wide support for the achievement of AQO through the LTP, the two groups identified differences in time-scale for delivering both policies, prioritisation of air quality within LTP, and unequal expectations as major factors affecting the integration. These factors indicate the existence of institutional complexities between parallel policy communities in ensuring integration.

Keywords: Local Air Quality Management (LAQM), Local Transport Plan (LTP), policy integration, environmental health officers, transport planners. 


\section{Introduction}

Air quality and transport planning in England have a long history of targeted legislative and regulatory responses such as the Environment Act 1995 and Transport Act 2000, which established the Local Air Quality Management (LAQM) and Local Transport Planning (LTP) frameworks respectively. Although, both policies operate in separate institutional frameworks with different agendas and timetables, the contributions of transport-based sources to local air pollution has necessitated a more integrated approach. Part IV of the Environment Act 1995 provides the primary legislation for air quality management by requiring the Secretary of State to publish an air quality strategy (AQS). The strategy outlines methods and targets to be pursued by the UK Government and the Devolved Administrations of Scotland, Wales and Northern Ireland based on health effects standards and objectives for eight pollutants, seven of which are managed at the local scale through the LAQM regime [1]. The key aspect of this regime, as required in the legislation, is the review and assessment of local air quality against the seven pollutants. District councils, unitary and metropolitan authorities are therefore required by legislation to review air quality within their jurisdiction and assess whether the air quality standards and objectives are being achieved. In areas where these objectives may be compromised by the target date set in the NAQS, the local authorities are required to designate such as Air Quality Management Areas (AQMA) and put in place an Air Quality Action Plans (AQAP) to improve the local air quality [2].

The review and assessment process is designed to identify those areas where poor air quality coincides with public exposure [3]. Central Government has issued a series of descriptive guidance documents, accompanied by training sessions and helpdesks facilities to assist the local authorities in carrying out this process. The responsibility for managing the process at the local government level is usually undertaken by the environmental health department or their equivalent as a phased exercise which increases in depth and complexity consistent with the level of risk of failing to achieve the objectives [4]. (See Beattie et al. [5] and Longhurst et al. [6] for a full description of the Review and Assessment process.) Local authorities in England are currently undergoing the third round of the review and assessment process, resulting in the declaration of AQMA by over 205 local authorities in April 2007, accounting for 47\% of local authorities in the UK [7]. Over $90 \%$ of AQMA declared, so far, were as a result of predicted exceedence in annual mean Nitrogen Dioxide $\left(\mathrm{NO}_{2}\right)$ and short-term $\mathrm{PM}_{10}$ objectives [8]. Both pollutants are largely due to traffic emissions from road transport sources, thereby undermining the power of LAQM, regardless of its intents and purposes, to remediate poor local air quality by itself. This creates an obvious limitation in the LAQM process in terms of policy disconnect between the diagnosis of the problem and the solutions proffered. While the review and assessment is effective in identifying the air pollution 'hot-spots' for subsequent declaration of an AQMA, the action planning is improperly calibrated as a policy instrument to the scale and nature of the discovered problem. 
This is part of the necessity for the introduction of a parallel, but potentially more powerful, policy framework through which the traffic-related air pollution identified in the review and assessment can be properly addressed. In the Local Government White Paper, Strong Local Leadership - Quality Public Services, the government stated that it no longer require from the local authorities "the production of a separate air quality management action plan where an air quality problem arises because of transport pollution. Instead, councils will be free to address this through their local transport plan" [9]. In subsequent government guidance documents for LAQM, the integration of air quality action plans into the LTP was explicitly required for AQMA that have been declared due to traffic-related exceedences for roads that are under the jurisdiction of the local transport authority and falling within the scope of the LTP [10].

The current transport planning framework, LTP, was introduced in 1998 through the White Paper “A New Deal for Transport: Better for everyone” [11]. The subsequent legislation, Transport Act 2000 therefore require most local authorities in England (apart from Greater London) to produce a LTP as a form of financial bidding document submitted to the central government every five years, outlining comprehensive integrated transport strategies which will be implemented in this period. The LTP is aimed at ensuring certainty of funding for public transport initiatives to the local authorities, underpinned by a performance-based funding allocation system which is monitored and assessed by the government against a set of targets and objectives established in the LTP guidance documents [11]. The second round of the process which commenced in 2006 identified four shared priorities agreed between central government and the Local Government Association; congestion, accessibility, safety and air quality [12]. While the inclusion of air quality as a shared priority within the second round of LTP can be perceived as a required boost for achieving trafficrelated air quality objectives within LAQM, there are potential limitations which may be due to the complex institutional arrangements in which both policy processes operate.

LAQM and LTP operate as two parallel frameworks with separate agendas and timetables, and are managed at the central government level by the Department for Environment, Food and Rural Affairs (Defra) and Department for Transport (DfT) respectively. At the local level, the responsibilities for LTP and LAQM are often in different departments within the local authority. Adequate connectivity between both policy packages is thereby dependent on the kind and level of inter-professional engagement between the departments and officials responsible for both policies at every level of government involved. Such engagement sometimes cuts across authorities due to variations in the institutional arrangements in which both policy processes operate (Fig. 1). English local governments operate either as a two-tier system where there is separation of functions between the upper-tier county council and the lower-tier district authorities, or in a single all-purpose system where a single unitary and metropolitan authority is responsible for all the local governments functions. However, some of the functions in an all-purpose system are often shared statutorily between metropolitan authorities (such as the Passenger Transport 
Executives (PTE) that manages public transport on behalf of joint metropolitan authorities) or non-statutorily between unitary authorities with historical or geographical affiliation (such as in the case of unitary authorities having joint LTPs with neighbouring authorities as they share similar travel to work areas) [13]. The requirement for inter-professional collaboration between the transport planners (TP) responsible for the LTP and environmental health officials (EHO) responsible for the LAQM may be more complicated in a two-tier system where the air quality is traditionally managed by the lower tier authorities and the LTP by the county council (upper tier). In such arrangements there are possibilities for conflicts of priorities and resource allocation which are further compounded by the disparity in the time-scales of delivering both the LAQM and LTP framework.

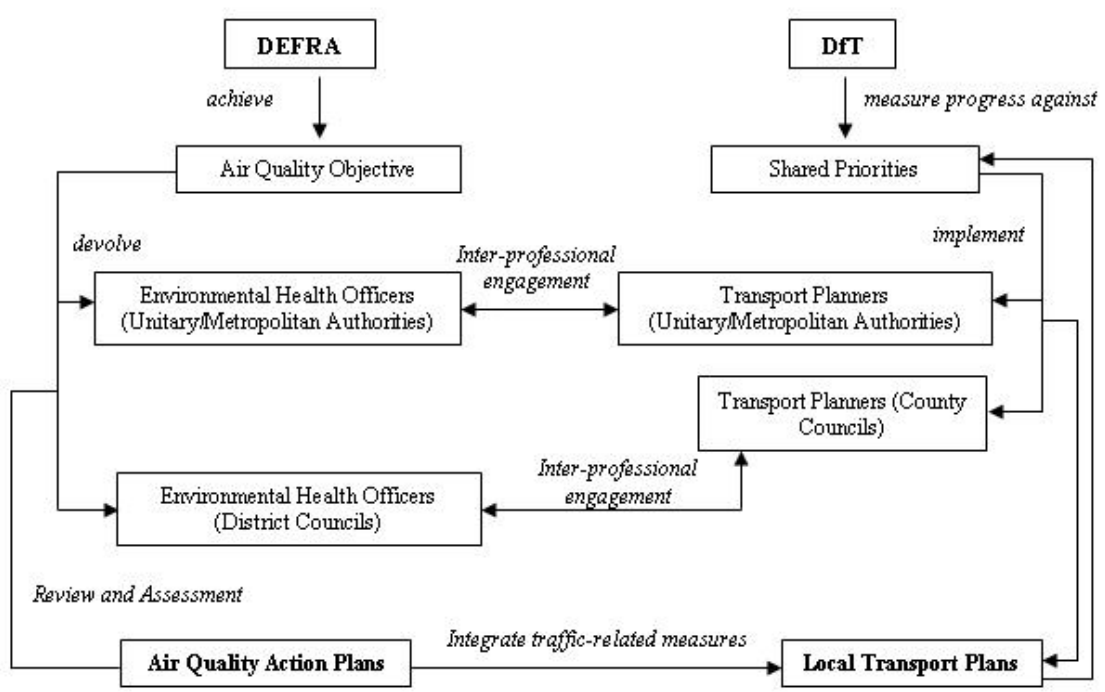

Figure 1: Institutional complexities involved in integrating air quality action plans into the local transport planning process in English local authorities.

Therefore, it can be argued that the success of achieving air quality objective (AQO) on the back of LTP is reliant on the capability of the process to overcome administrative complexities, conflicting timescales and other challenges of integration. This paper examines the perspectives and attitudinal approach of the primary stakeholders in the process (EHOs and TPs) towards the integration of both policies, and how this might influence the effectiveness of achieving the traffic-related AQO in the English local authorities. Evidence is presented from a web-based questionnaire survey of EHOs and TPs in over 200 local authorities between July and September 2007 as part of a three-year investigation into the effectiveness of integrating air quality into the LTP in England. 


\section{Methodology}

Districts, unitaries and metropolitan authorities in England with current trafficrelated AQMAs were identified from the Review and Assessment database held on behalf of Defra and the Devolved Administration at the University of the West of England, Bristol (UWE). The EHO from these authorities were selected for the survey due to the significance of transport-related issues in the preparation of their air quality action plans. The transport planning departments of local transport authorities such as counties and passenger transport authorities (PTA) or unitary authorities that included one or two authorities with trafficrelated AQMA were selected due to the specific requirement for integrating air quality within their LTP. Specific EHO or TP whose responsibilities in the department included air quality management or LTP preparation respectively were selected and contacted for the survey. In some cases, the questionnaire was sent to a senior manager in the department with the expectation that it might be delegated it to the relevant officer.

The questionnaire was administered to 142 EHOs and 85 TPs through a weblink which further aids the retrieval and analysis of the questionnaire results. Responses were received from 70 EHOs and 41 TPs, an average of 49\% response rate from both groups. The responses cut across the four major types of local authorities and all the regions in England (outside London). The questionnaire utilised the mixture of both the open-ended and close-ended questions. This is aimed at gathering as much detailed, yet structured information as possible within the limited available time and space. The data collected from both questionnaires was analysed using Statistical Package for Social Scientists (SPSS).

\section{Results and discussion}

By January 2005, at the time of preparing draft LTP2 documents, 138 local authorities in the UK had declared at least one AQMA, 90\% of which were designated due to traffic emissions [14]. Due to the explicit requirement for the integration of action plans for traffic-related AQMA into the LTP2, it is expected that most of the AQMA declared by this time will be properly integrated into the LTP. However, $63 \%$ of the EHO surveyed said that their action plans were not integrated into the final LTP2, while $79 \%$ of the TP respondents acknowledged that the action plans were not effective for use during the preparation of the LTP.

These responses are indicative of some other factors which might influence the integration of both policies, three of which were identified in the survey.

\subsection{Difference in timetable}

First, an average of $60 \%$ from both groups recognised the disparity in the timescales for achieving both the LAQM and LTP framework as a constraint to integration. $57 \%$ of $\mathrm{EHO}$ and $54 \%$ of TP respondents admitted that the action 
plans were not ready before the LTP submission deadline, thereby making it impossible for its integration into the final draft. In an attempt to overcome problems posed by this situation, the DfT recommended a new LTP progress reporting system starting from 2008, which will provide 'broader-based reviews, enabling authorities not only to assess their progress in meeting their objectives and targets during the first two years of [LTP2], but to consider any opportunities or threats to the effective delivery of the LTP2s in their remaining years' [15]. This is intended to encourage local authorities who had missed the opportunity of integrating their actions plans into the final document at the time of the submission in 2006 to use the 2008 Progress Report as a means of so doing.

\subsection{Degree of prioritising air quality within LTP}

The second factor identified by both groups is the prioritisation of air quality within LTP. Although the Government through the DfT seeks the delivery of each of the shared priorities within the LTP, on the other hand, it provides opportunities for local authorities to decide the relative importance given to each priority in their area [12]. Table 1 presents the mean of Likert scale responses from the TP on the comparison of importance of the LTP priorities based on time, resources and fund allocation. Only 30\% EHO disagreed with the statement that "the transport planners do not put enough importance to achieving the air quality objectives within the LTP2" this may be connected to the fact that other priorities such as safety, congestion and accessibility have longer histories of policy responses within the transport planning framework than air quality. Also, it can be argued that there are higher public opinion and concern over these priorities than air quality at the local level, thereby giving them political advantage over the latter. This is reflected in the way air quality is treated within the LTP. $42 \%$ of the EHO and $29 \%$ of the TP respondents thought that air quality is considered less important by the planners when preparing the LTP. However, in shire counties, metropolitan authorities or joint unitaries where an LTP covers more than one local authority, the risk of the air quality profile being reduced within the transport strategy was even greater if air quality problems arose in just one of the authorities. This view is echoed in these responses:

"Differing political priorities [is another reason why our local authority find it difficult to integrate action plans into LTP2]. It was politically uncomfortable for our county council to recognise the existence of one of our AQMAs and as a consequence, our action plan for this area was excluded from the LTP."

[EHO from a district authority in the East Midland region of England]

"Our AQMAs are very small and are stated by the county council as not 'even being on their list of problems areas."

[EHO from a district authority in the South East region of England] 
Table 1: $\quad$ Mean of responses showing importance placed on priorities within LTP by the TP based on time, resources and fund allocation, where $1=$ very high priority, $6=$ very low priority $(\mathrm{N}=$ number of $\mathrm{TP}$ respondents).

\begin{tabular}{lll}
\hline PRIORITIES & N & MEAN (1-6) \\
\hline Safety & 41 & 1.46 \\
\hline Congestion & 41 & 2.02 \\
\hline Accessibility & 41 & 2.05 \\
\hline Other Local Priorities & 39 & 2.33 \\
\hline Air Quality & 41 & 2.98 \\
\hline
\end{tabular}

The low relative importance of air quality within LTP raises a particular question on the implications of this on LAQM, given the broad support for the implementation of air quality through the transport planning (Fig. 2). This question leads to the third factor on the level of inter-professional working required by both groups for integration.
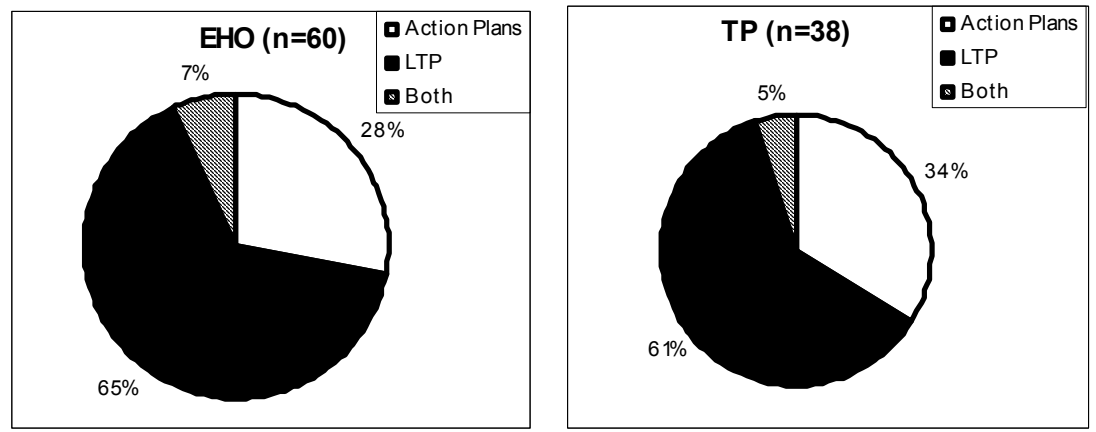

Figure 2: $\quad$ EHO and TP responses to question: In addressing transport-related AQ problems in your LA, which approach do you think is more effective?

\subsection{Inter-professional engagement}

Good communication and inter-professional engagement between the EHO and $\mathrm{TP}$ in promoting the air quality management profile within the LTP is crucial to the successful integration of both policies. However, the demonstration of such engagement in the LTP process is relatively weak as evidenced in the questionnaire survey. Although $23 \%$ of EHO and $12 \%$ of TP respondents agreed that the communication between both groups is very poor, there were disparities of opinion between both groups on the timing of consultation and the quality of communication necessary to integrate both policies. Despite the fact that over $90 \%$ of both groups surveyed agreed that the TP consulted with the EHO on 
LTP, only $39 \%$ of EHO respondents thought that the consultation was early as compared to the $63 \%$ of TP respondents who considered it to be so. In addition, there were dissimilar perceptions on the quality of the communication between both groups, while $62 \%$ of TP respondents thought that the communication was sufficient to facilitate the integration, only $21 \%$ of the EHO respondents agreed with this.

Subsequently, lower percentage of EHO respondents (32\%) thought that such communication is effective in comparison to $66 \%$ of TP respondents who considered it to be effective. It is therefore apparent that there are unequal expectations on the level of inter-professional engagement between both groups. As illustrated in Figure 3, there are sharp differences in the reflections of both groups regarding the attention given to the action plans by the TP during the implementation of LTP2. Such dichotomy is also reflected in their level of optimism towards addressing transport-related air quality problems through the LTP. Fewer EHO respondents (6\%) thought that the integration has been successful in solving the problem, in comparison to $43 \%$ of TP respondents who think so. However, it can be argued that, rather than misconstruing the existing dichotomy between both groups as lack of support for air quality within LTP, it should be viewed as evidence of the existence of institutional complexities between parallel policy communities in ensuring integration. This argument is supported by a comment from one of the TP respondent:

"As with many joint ventures, successful operation requires that a measure of trust is built up between all involved. Two sets of professionals with different backgrounds and priorities will have different takes on the same subject. Progress is made by identifying shared problems and each contributing what they can towards solutions."

[TP from unitary authority in the East Midlands region of England]
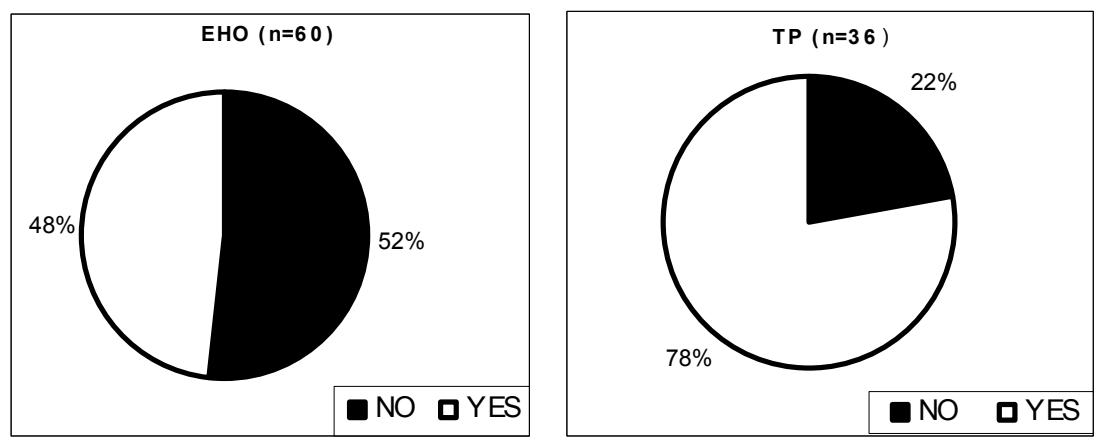

Figure 3: $\quad$ EHO and TP responses to question: Do you think the transport planners paid enough attention to the Action Plan during the implementation of the LTP2? ( $\mathrm{n}=$ number of respondents). 


\section{Conclusions}

While there is wide support for the achievement of traffic-related air quality objectives through the LTP, integrating both policies has been challenging due to timetable differences, differing interpretations by local authorities regarding the degree of prioritisation of air quality within LTP, and unequal expectations of both groups involved in the process. These factors are connected to the difficulties of facilitating wider collaboration and engagement between the two major stakeholders. Consequently, the existence of a collaborative platform, where the communication between the EHO and TP is promoted to a level acceptable and accessible to both groups, has positive potential for promoting the necessary integration.

\section{Acknowledgements}

The authors will like to thank Defra for allowing access to the review and assessment database, and the local authorities involved in this study for their participation.

\section{References}

[1] HM Government, Environment Act 1995. The Stationary Office: London, 1995.

[2] Department for Environment, Transport and the Regions, The Air Quality Strategy for England, Scotland, Wales and Northern Ireland - Working Together for Clean Air. The Stationary Office: London, 2000.

[3] Beattie, C.I., Longhurst, J.W.S. and Woodfield, N.K., Air Quality Management: evolution of policy and practice in the UK as exemplified by the experience of English local government. Atmospheric Environment, 35, pp.1479-1490, 2001.

[4] Department for Environment, Food and Rural Affairs, National Assembly for Wales, Scottish Executive and Department of the Environment for Northern Ireland, Part IV of the Environment Act 1995 Local Air Quality Management. Technical Guidance LAQM, TG(03), Defra: London, 2003.

[5] Beattie, C.I., Chatterton, T.J., Hayes, E., Leksmono, N., Longhurst, J.W.S. and Woodfield, N.K., Air Quality Action Plans in the UK: an overview and evaluation of process and practice. Proc. of the $14^{\text {th }}$ Int. Conf. on Modelling, Monitoring and Management of Air Pollution, eds. J.W.S. Longhurst \& C.A. Brebbia, WIT Press: Southampton, pp. 503-512, 2006.

[6] Longhurst, J.W.S., Beattie, C.I., Chatterton, T.J., Hayes, E.T., Leksmono, N. S. and Woodfield, N. K., Local air quality management as a risk management process: Assessing, managing and remediation the risk of exceeding an air quality objective in Great Britain. Environment International, 32, pp. 934-947, 2006.

[7] Hayes, E.T., Leksmono, N.S., Chatterton, T.J., Symons, J.K., Baldwin, S.T., and Longhurst, J.W.S., Co-management of carbon dioxide and local 
air quality pollutants: identifying the 'win-win' actions. Proc. Of the $14^{\text {th }}$ IUAPPA World Congress, Brisbane, Australia, 2007.

[8] Chatterton, T.J, Woodfield, N.K., Beattie, C.I., and Longhurst, J.W.S., Outcomes of the first round of local authority air quality Review and Assessments under the UK's Air Quality Strategy. Journal of Environmental Monitoring, 6, pp. 849-853. 2004.

[9] Strong local leadership - Quality public services; UK. Department for Transport, Local Government and the Regions, 2001White Paper Online. http://www.communities.gov.uk/documents/localgovernment/pdf/143810

[10] Department for Environment, Food and Rural Affairs, National Assembly for Wales, Scottish Executive and Department of the Environment for Northern Ireland, Part IV of the Environment Act 1995 Local Air Quality Management. Policy guidance: Addendum LAQM, PGA (05), Defra: London, 2005.

[11] A New Deal for Transport; UK. Department of the Environment, Transport and the Regions, 1998 White Paper Online. www.dft.gov.uk/stellent/groups/dft_about/documents/pdf/dft_about_pdf_0 21588.pdf

[12] Department for Transport, Full Guidance on Local Transport Plans: Second Edition. DfT: London, 2004.

[13] Shepherd, S. P., Timms, P.M. and May, A.D., Modelling requirements for Local Transport Plans: An assessment of English experience. Transport Policy, 13, pp. 307-317. 2006.

[14] Hassan, S. M., Evaluation of the local authority management process in Great Britain in its second round of Review and Assessment. PhD. Thesis University of the West of England, Bristol, Faculty of Applied Sciences, 2006.

[15] Department for Transport, Strengthening local delivery: the draft Local Transport Bill. HMSO: London, 2007. 